\title{
Response to Torday
}

Advance online publication, 31 May 2017; doi:10.1038/pr.2017.84

To the Editor: We thank Dr. Torday (1) for his thoughtful comments on our review "What is the identity of fibroblast pneumocyte factor?". His thoughts are particularly valuable as he has worked in this field almost from its beginning, producing the greater part of the work on leptin and surfactant. His comments raise some points that we want to address. We missed citing the study by DeBlasio et al. (2), who reported that recombinant sheep leptin stimulated surfactant protein B mRNA in the sheep lung; this is in contrast to the work of Sato et al. (3) who used recombinant human leptin in sheep. Our omission was inadvertent, and not a selection bias. The study by De Blasio et al. did not come to our attention, as it was published a few days before our submission. Species specificity of leptin could explain the differences between the two studies. However, De Blasio et al. did not investigate the impact of leptin on surfactant phospholipid synthesis and found no effect on other surfactant protein mRNAs. Thus, the importance of leptin in stimulating overall surfactant synthesis in sheep remains unclear. Our statement that more work is needed to explain why leptin appears important in some species but not in others remains valid.

We feel our discussion of lipofibroblasts in human lungs was appropriately balanced. Instead of citing the study by Rehan and co-workers (4) we chose to cite a more recent paper by Rehan and Torday (5) for their statement that leptin control of type II cell surfactant production during development depends on the presence of lipofibroblasts. We cited the study by Tahedl et al. (6), the most current discussion of mammalian pulmonary lipofibroblasts, which concluded that lipofibroblasts are restricted to mice, rats, and rabbits. Despite Torday's statement that lipofibroblasts were "unequivocally" demonstrated in human lungs by Rehan et al. in 2006, numerous other skilled investigators in the field clearly remain skeptical. We stand by our conclusion that the existence of human pulmonary lipofibroblasts is controversial.
We thank Torday for introducing the importance of androgens in fibroblast-type II cell communication in lung development, including the response to glucocorticoids. The clinical and developmental importance of sex differences in lung development is underappreciated. Androgen inhibits the stimulatory effects of fibroblast pneumocyte factor (FPF). Both Torday and one of us (H.C.N.) have contributed substantially on this topic. We had to omit this and other topics of value because of size constraints. Androgen-leptin interactions have been reported. We support the need for studies that describe how androgen affects the synthesis, secretion, or action of keratinocyte growth factor and neuregulin- $1 \beta$. We believe that such studies will add another interesting facet to the question of the identity of FPF.

\section{STATEMENT OF FINANCIAL SUPPORT}

This study was supported by NIH NHLBI HL085648.

Disclosure: The authors declare no conflict of interest.

\section{Heber C. Nielsen ${ }^{1}$, George King ${ }^{2}$ and Max H. Cake ${ }^{2}$ ${ }^{1}$ Department of Pediatrics, Graduate Program in Cell and Molecular Developmental Biology, Tufts Medical School, Boston, Massachusetts; ${ }^{2}$ School of Veterinary and Life Sciences, Murdoch University, Perth, Western Australia.}

Correspondence: Heber C. Nielsen (heber.nielsen@tufts.edu)

\section{REFERENCES}

1. Torday, JS. Commentary on "What is the identity of fibroblast pneumocyte factor (FPF)?" Pediatric Research 2017;81:391.

2. De Blasio MJ, Boije M, Kempster SL, et al. Leptin matures aspects of lung structure and function in the ovine fetus. Endocrinology 2016;157: 395-404.

3. Sato A, Schehr A, Ikegami M. Leptin does not influence surfactant synthesis in fetal sheep and mice lungs. Am J PhysiolLung Cell Mol Physiol 2011;300:L498-505.

4. Rehan VK, Sugano S, Wang Y, et al. Evidence for the presence of lipofibroblasts in human lung. Exp Lung Res 2006;32:379-93.

5. Rehan VK, Torday JS. PPAR $\gamma$ signaling mediates the evolution, development, homeostasis, and repair of the lung. PPAR Res 2012;2012: 289867.

6. Tahedl D, Wirkes A, Tschanz SA, Ochs M, Muhlfeld C. How common is the lipid body-containing interstitial cell in the mammalian lung? Am J Physiol Lung Cell Mol Physiol 2014;307:L386-94. 